Научная статья

УДК 332.142

DOI 10.18101/2304-4446-2020-4-133-138

\title{
ПРОБЛЕМЫ РАЗРАБОТКИ РЕГИОНАЛЬНЫХ ПРОГРАММ ОХРАНЫ ОКРУЖАЮЩЕЙ СРЕДЫ
}

\author{
(C) Убонова Дарима Зориктоевна \\ младший научный сотрудник, \\ Бурятский научный центр СО РАН \\ Россия, 670047, г. Улан-Удэ, ул. Сахьяновой, 8 \\ darimaub@mail.ru
}

Аннотация. В статье проведен анализ существующих проблем при разработке региональных экологических программ. Исследован опыт российских регионов по разработке инструментов государственной политики, направленной на сбалансированное решение экологических и социально-экономических проблем. Обоснована необходимость разработки отдельных программных документов с учетом действия особого режима природопользования. Исследованы организационные, управленческие и методические проблемы разработки региональных экологических программ. Рассмотрены вопросы согласования интересов государства, населения и бизнес-структур. Выявлена проблема верификации данных при оценке эффективности экологических мероприятий. Исследовано ресурсное обеспечение расходов на реализацию программ за счет всех источников финансирования, выявлено преобладание средств федерального бюджета. Показана целесообразность широкого общественного обсуждения проектов экологических программ и проведения качественного отбора мероприятий для последующего согласования с федеральными органами власти.

Ключевые слова: региональные программы; охрана окружающей среды; экологические мероприятия; финансирование; общественное обсуждение.

\section{Для цитирования}

Убонова Д. 3. Проблемы разработки региональных программ охраны окружающей среды // Вестник Бурятского государственного университета. Экономика и менеджмент. 2020. № 4. С. 133-138.

Проблемы охраны окружающей среды относятся к ключевым вопросам устойчивого развития территорий. Актуальной задачей является разработка эффективных инструментов региональной политики, направленных на сбалансированное развитие социо-эколого-экономических систем [1]. Особое значение это имеет для территорий, характеризующихся высокой степенью уязвимости природной среды от воздействия антропогенных факторов. К ним относятся ресурсные регионы, экономика которых базируется на использовании имеющихся природных ресурсов [2;3].

В условиях неожиданных стрессов и потрясений современной эпохи повышается значимость экологического территориального планирования [4], совершенствования хозяйственного механизма управления [5].

В российских регионах накоплен значительный опыт разработки и реализации организационно-экономических и административно-правовых мероприятий, 
направленных на минимизацию деструктивного воздействия хозяйствующих субъектов на окружающую среду [6]. В России и в зарубежных странах активно разрабатываются региональные экологические программы, проводятся исследования причин и возможные экологические последствия сохранения существующих тенденций природопользования $[7 ; 8]$. Для формирования эффективной государственной экологической политики важное значение имеет сочетание как простых ограничительных мер, так и комплексных мер, включающих инструменты экономического стимулирования [9].

Вместе с тем на практике в стратегиях социально-экономического развития экологический компонент не всегда получает адекватное отражение. Неустойчивость финансирования природоохранных программ часто приводит к отсрочке реализации запланированных мероприятий [10]. Экологические программы нередко характеризуются недостатками в методологии, системности и обоснованности экономических и экологических эффектов от реализации запланированных мероприятий [11].

Вопросы разработки и реализации программ по охране окружающей среды являются актуальными в Республике Бурятия, которая относится к регионам России, характеризующимся сложной экологической ситуацией. В значительной степени это обусловлено воздействием особого режима природопользования на Байкальской природной территории.

Решение этих проблем определяет необходимость разработки и реализации специальных экологических программ. Следует отметить особую сложность таких программ, связанную с согласованием вопросов по множеству проблем.

Во-первых, это касается сбалансированности развития территории с учетом экологического, экономического и социального факторов. Одновременно достичь оптимальных показателей по всем трем направлениям невозможно. Так, например, увеличение производства, как правило, ведет к ухудшению состояния окружающей среды. С другой стороны, введение экологических ограничений угнетающе действует на экономику соответствующей территории. Свидетельством этого являются негативные экономические и социальные последствия запрета на вылов байкальского омуля: жители прибрежных населенных пунктов лишились традиционного источника доходов. Какой-либо альтернативной занятости им предложено не было.

Во-вторых, сложной проблемой является согласование зачастую противоречивых интересов действующих акторов, к которым следует отнести государство, население и бизнес-структуры. Предприниматели стремятся к получению прибыли путем увеличения действующих и создания новых производств. Государственные органы власти должны быть нацелены на повышение экономической активности на соответствующей территории, сохранение и создание новых рабочих мест, увеличение налоговых поступлений. Вполне естественна заинтересованность населения в активизации экономической деятельности, но при условии сохранения качества жизни, важнейшим критерием которого является благоприятная экологическая обстановка. В случае возможного ухудшения состояния окружающей среды оно выступает против реализации инвестиционных проектов бизнес-структур. Свидетельством этого являются выступления населения и общественности Закаменского района Республики Бурятия против предоставления 
аренды лесных участков для заготовки древесины и пиломатериалов. С другой стороны, неожиданный для предпринимателей отказ от реализации запланированных проектов негативно влияет на инвестиционную привлекательность региона. Все это определяет необходимость установления ясных и однозначных условий осуществления хозяйственной деятельности, воздействующей на окружающую среду, которые должны быть понятны всем заинтересованным лицам.

В-третьих, при разработке региональных программ существуют проблемы их увязки и согласования на различных уровнях. Субъект Российской Федерации, по сути, является «срединным» между федеральными и местными органами власти. Не всегда между ними имеет место совпадение интересов и возможностей (ресурсов).

Наряду с вопросами организационного и управленческого характера разработки региональных экологических программ существуют серьезные методические проблемы. В значительной мере они связаны с известными недостатками в системе стратегического планирования. К сожалению, несмотря на принятие в 2014 г. соответствующего федерального закона ${ }^{1}$, методическая база по разработке региональных документов стратегического планирования далека от совершенства. В настоящее время преобладает проектный подход, направленный, как правило, на решение конкретной узкой задачи. Напротив, экологические проблемы следует рассматривать в увязке с экономическими и социальными аспектами развития территории, что требует более широкого, системного подхода, который можно реализовать в рамках специальных программ.

Остаются нерешенными многие вопросы по оценке эффективности экологических мероприятий. В значительной степени это вызвано проблемой верификации данных. Не всегда удается в полной мере использовать объективную информацию, включая данные Росстата, Пенсионного фонда, Налоговой службы, Росприроднадзора и других государственных органов Российской Федерации.

Целый блок проблем связан с процедурами разработки и отбора мероприятий экологических программ. Здесь следует учитывать ряд аспектов. С одной стороны, без широкого общественного обсуждения невозможно представить мероприятия, охватывающие интересы значительной части населения. Речь идет о наиболее актуальных экологических проблемах.

К таковым, на наш взгляд, относятся вопросы загрязнения атмосферного воздуха в Улан-Удэ в осенне-зимний период. Практически все жители города с численностью населения около 500 тысяч человек вынуждены дышать грязным воздухом, что негативно влияет на состояние здоровья и другие аспекты жизнедеятельности. Запретительными методами здесь не обойтись. Для решения этой проблемы нужен системный подход. По мнению автора необходима отдельная региональная программа или подпрограмма. Для ее разработки целесообразно активное привлечение специалистов и экспертов, в том числе из профильных научных организаций. Это позволит повысить обоснованность предлагаемых мероприятий и процедур.

\footnotetext{
${ }^{1}$ О стратегическом планировании в Российской Федерации: федеральный закон от 28 июня 2014 г. N 172-ФЗ.
} 
Одной из наиболее значимых проблем при разработке региональных программ по охране окружающей среды является вопрос финансирования. Рассмотрим его на примере экологических программ, принятых в Республике Бурятия.

Во-первых, следует обратить внимание на снижение объема финансирования Если в республиканской целевой программе «Экологическая безопасность в Республике Бурятия на 2009-2011 годы и на период до 2020 г.» запланированная величина составляла 36,5 млрд р. (по 3 млрд р. ежегодно), то в государственной программе Республики Бурятия «Охрана окружающей среды и рациональное использование природных ресурсов» объем финансирования значительно снизился и составил 9,5 млрд р., т. е. по 730 млн р. ежегодно (табл. 1).

Таблица 1

Источники и структура финансирования экологических программ

\begin{tabular}{|l|c|c|c|c|}
\hline \multirow{1}{*}{$\begin{array}{l}\text { Источник } \\
\text { финансирования }\end{array}$} & \multicolumn{2}{|c|}{$\begin{array}{c}\text { РЦП «Экологическая безопасность } \\
\text { 2009-2020" }\end{array}$} & \multicolumn{2}{c|}{$\begin{array}{c}\text { Госпрограмма «Охрана } \\
\text { окружающей среды 2014-2026» }\end{array}$} \\
\cline { 2 - 5 } & млн руб. & $\%$ & млн руб. & $\%$ \\
\hline Всего & 36532,7 & 100,0 & 9504,5 & 100,0 \\
\hline $\begin{array}{l}\text { Федеральный } \\
\text { бюджет }\end{array}$ & 28739,5 & 78,6 & 5882,2 & 61,9 \\
\hline $\begin{array}{l}\text { Республиканский } \\
\text { бюджет }\end{array}$ & 5374,5 & 14,7 & 2396,1 & 25,2 \\
\hline Местный бюджет & 888,5 & 2,4 & 13,4 & 0,1 \\
\hline Юридические лица & 1530,2 & 4,3 & 1212,8 & 12,8 \\
\hline
\end{tabular}

Во-вторых, значительно (почти в 2 раза) возросла доля финансирования из регионального бюджета при существенном снижении удельного веса федеральных средств. На наш взгляд, для бюджета Республики Бурятии, характеризующегося хроническим дефицитом, такая ситуация затруднительна. Для финансирования региональных экологических программ необходимо максимальное взаимодействие с государственными заказчиками федеральных программ, а также привлечение инвестиций на основе государственно-частного партнерства.

В целом следует отметить необходимость проведения качественного отбора мероприятий для последующего согласования с федеральными органами власти. Высокая значимость проблемы охраны окружающей среды для проживающего населения определяет целесообразность широкого общественного обсуждения проектов региональных экологических программ.

\footnotetext{
1 О республиканской целевой программе «Экологическая безопасность в Республике Бурятия на 2009-2011 гг. и на период до 2020 года»: постановление Правительства Республики Бурятия от 31 июля 2009 г. N 301.

2 О Государственной программе Республики Бурятия «Охрана окружающей среды и рациональное использование природных ресурсов»: постановление Правительства Республики Бурятия от 30 мая 2013 года N 261.
} 


\section{Литература}

1. Котов А. В. Оценка эффективности инструментов региональной политики // Экономика региона. 2020. Т. 16, вып. 2. С. 352-362.

2. Направления сбалансированного социально-экономического развития Арктической зоны России (на примере Якутии) / В. И. Денисов [и др.] // Проблемы прогнозирования. 2020. № 4(181). С. 66-73.

3. Замятина М. Ф., Дьяков М. Ю. Ресурсный и экологический подходы к развитию региона: опыт сравнительного анализа на примере Камчатского края // Известия Русского географического общества. 2018. Т. 150, № 4S. С. 3-14.

4. Фоменко Г. А., Фоменко М. А. Современные тенденции и особенности экологического территориального планирования // Проблемы региональной экологии. 2018. № 5. C. $154-164$.

5. Гусев А. А. Хозяйственный механизм управления охраной окружающей среды и природопользованием пути развития эколого-экономического нормирования // Экономика природопользования. 2018. № 3. С.4-10.

6. Анопченко Т. Ю., Мурзин А. Д., Ревунов Р. В. Состояние экологической сферы и векторы повышения эффективности рационального природопользования в Ростовской области // Экономика и экология территориальных образований. 2019. Т. 3, № 2. С. 5764.

7. Мурзин А. Д., Мурзина С. М. Анализ практики реализации региональных экологических программ в России и за рубежом // Экономика и экология территориальных образований. 2017. № 2. С. 124-133.

8. Власенко Т. В., Ксенз В. Я. Современные экологические программы Ростовской области // Экономика и экология территориальных образований. 2015. № 4. С. 81-85.

9. Ершов Д. Н. Эколого-экономическое регулирование в США и Канаде: уроки для России // Экономика природопользования. 2020. № 1. С. 35-49.

10. Новоселов А. Л., Новоселова И. Ю. Финансирование природоохранной программы: обоснование и оптимизация // Проблемы региональной экологии. 2019. № 3. С. $87-$ 90.

11. Михеева А. С., Аюшева С. Н., Ботоева Н. Б. Теория и практика определения эффективности капитализации средозащитных затрат государственных программ и проектов // Экономика природопользования. 2018. № 4. С. 56-65.

\section{PROBLEMS OF DEVELOPING REGIONAL ENVIRONMENTAL PROGRAMS}

Darima Z. Ubonova

Junior Researcher,

Buryat Scientific Center SB RAS

8 Sakhyanovoy St., Ulan-Ude 670047, Russia

darimaub@mail.ru

Abstract. The article analyzes the current problems in development of regional environmental programs, in particular the experience of Russian regions in the implementation of national policy tools aimed at a balanced solution of environmental and socio-economic problems. We have substantiated the necessity of developing separate program documents, taking into account the special model of nature management. The article considers the organizational, managerial and methodological problems of regional environmental programs development, as well as the issues of coordinating interests of the state, population and business structures. We have revealed the problem of data verification in assessing the effectiveness of environmental measures, and the predominance of federal budget funds in the re- 
source provision of expenses for the implementation of programs. It is emphasized the expediency of a broad public discussion of draft environmental programs and careful choice of events for subsequent coordination with federal authorities.

Keywords: regional programs; environmental protection; environmental activities; financing; public discussion.

Статья поступила в редакцию 16.10.2020; одобрена после рецензирования 30.10.2020; принята к публикации 30.10.2020. 